\title{
Relationship between Leaf Surface Characteristics and Particle Capturing Capacities of Different Tree Species in Beijing
}

\author{
Weikang Zhang ${ }^{1,2}$, Bing Wang ${ }^{2,3}$ and Xiang Niu ${ }^{2,3, *}$ \\ 1 College of Forestry, Shenyang Agriculture University, Shenyang 110866, China; zhwk123456789@163.com \\ 2 Research Institute of Forest Ecology, Environment and Protection, Chinese Academy of Forestry, \\ Beijing 100091, China; wangbing@caf.ac.cn \\ 3 Beijing Collaborative Innovation Center for Eco-Environmental Improvement with Forestry and Fruit Trees, \\ Beijing 102206, China \\ * Correspondence: niuxiang@caf.ac.cn; Tel.: +86-10-62889334
}

Academic Editors: Jesus Julio Camarero, Raúl Sánchez-Salguero, Juan Carlos Linares and Timothy A. Martin Received: 30 November 2016; Accepted: 14 March 2017; Published: 20 March 2017

\begin{abstract}
Leaf surface is a multifunctional interface between a plant and its environment, which affects both ecological and biological processes. Leaf surface topography directly affects microhabitat availability and ability for deposition. In this study, atomic force microscopy (AFM) and the resuspended particulate matter method were applied to evaluate the adsorptive capacity of the leaf surface. Patterns of particulate-capturing capacities in different tree species and the effect of leaf surface features on these capacities were explored. Results indicated the following: (1) more total suspended particles (TSP) per unit leaf area were captured by coniferous tree species than by broad-leaved tree species in a particular order-i.e., Pinus tabuliformis > Pinus bungeana > Salix matsudana > Acer truncatum > Ginkgo biloba > Populus tomentosa; (2) Significant seasonal variation in particulate-capturing capacities were determined. During the observation period, the broad-leaved tree species capturing TSP and coarse particulate matter $\left(\mathrm{PM}_{10}\right)$ clearly exhibited a $\cap$-shape pattern - that is, increasing initially and later on decreasing; meanwhile, the $\cap$-shape pattern was not clearly shown in P. tabuliformis and P. bungeana. However, no obvious patterns in the absorption of fine particulate matter $\left(\mathrm{PM}_{2.5}\right)$ were found in the tested tree species; (3) The leaf surface topography, as observed by AFM and scanning electron microscopy, revealed that the broad-leaved tree exhibits a good correlation between micro-roughness of leaf surfaces and density of particles settling on leaf surfaces over time. However, the main factors affecting the adsorptive capacities of the leaves in coniferous trees are the number of stomata as well as the amount of epicuticular wax and the properties of the cuticle in different seasons.
\end{abstract}

Keywords: leaf structure; seasonal changes; $\mathrm{AFM}$; particulate matter; $\mathrm{PM}_{10} ; \mathrm{PM}_{2.5}$; roughness

\section{Introduction}

Global industrialization and rapid urbanization have led to an increase in air pollution, which is an urban environmental problem [1,2]. Air pollutants, particularly air particulate matter, present serious hazards to human health. If the amount of particulate matter in the air $\left(\mathrm{PM}_{10}\left(\mathrm{D}_{\mathrm{p}}<10 \mu \mathrm{m}\right)\right.$ or $\left.\mathrm{PM}_{2.5}\left(\mathrm{D}_{\mathrm{p}}<2.5 \mu \mathrm{m}\right)\right)$ increases by $10 \mu \mathrm{g} / \mathrm{m}^{3}$, the probability of asthma in children aged 1-3 y rises by $1.06 \%$ and $1.12 \%$, respectively [3]. Air particulate matter can result from direct emissions or as secondary products, both of which contain natural and anthropogenic sources (Figure 1). Natural sources include ground dust, foam and salt splashed from sea waves, ashes released from volcanic eruption, forest fires, plant pollen, and spores [4,5]. Anthropogenic sources mainly contain soot and 
dust produced during human activities and fossil fuel combustion, including mixtures of heavy metals and black carbons, polycyclic aromatic hydrocarbons, and other substances [6,7].

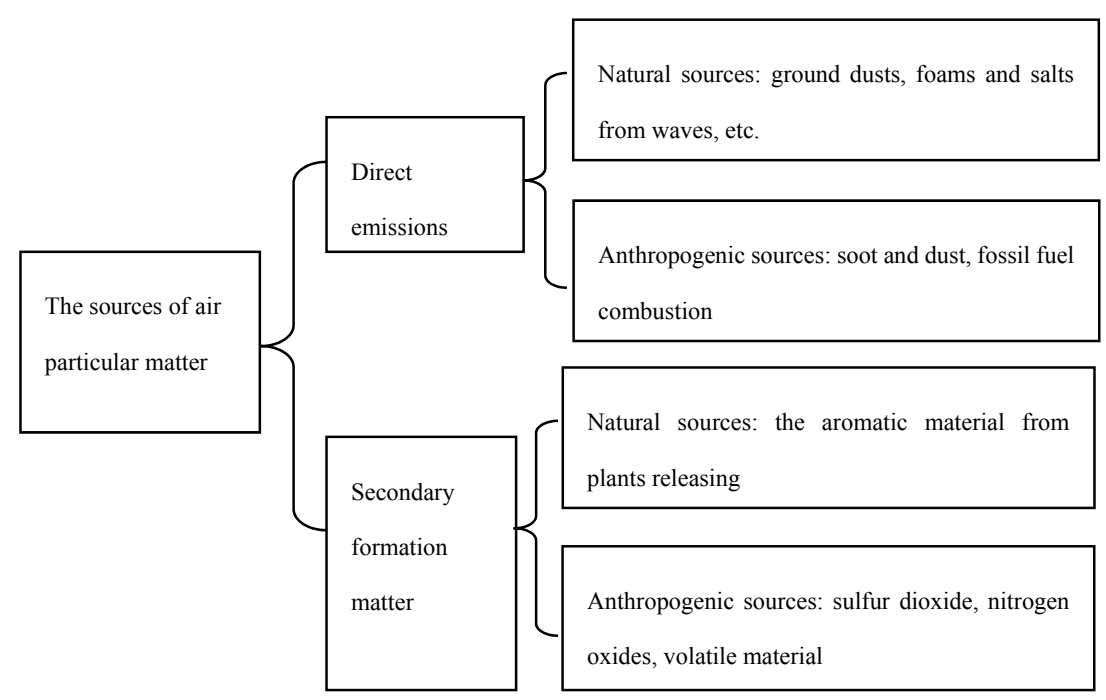

Figure 1. The main sources of air particulate matter.

The population and number of motor vehicles in Beijing, an international metropolis, have sharply increased with rapid economic development. According to statistics, the resident population of Beijing in 2013 was 21 million and the number of motor vehicles was 5.5 million [8]; the car: resident ratio was 1:4, which led to serious air pollution. In January 2013, incidents of strong haze pollution were reported in Beijing. The average concentration of $\mathrm{PM}_{2.5}$ reached $200 \mu \mathrm{g} \cdot \mathrm{m}^{-3}$, the total amount of air particulate matter in Beijing was greater than 4000 tons [9]. In February 2014, the $\mathrm{PM}_{2.5}$ concentrations in Beijing increased even further to $900 \mu \mathrm{g} \cdot \mathrm{m}^{-3}$, presenting certain risks to human health. A strategy to reduce the concentration of air particulate matter and to provide cleaner air needs to be developed. Two main ways of reducing air particulate matter are currently recognized: one method is to control the emission sources of particulate matter, such as by reducing emissions from factories, changing energy utilization, or reducing the number of cars; the other approach is to reduce the concentration of air particulate matter by capturing it, such as by the natural action of forest vegetation [10]. Vegetation can reduce air particulate matter in multiple ways. For example, vegetation can increase the surface roughness of the ground and reduce wind speeds. A lower wind speed can increase concentrations of pollutants owing to limited dispersion, which may lead to increases in the sedimentation rate of air particulate matter. Branches, leaves, and stems can capture air pollutant components (including total suspended particles (TSP), $\mathrm{CO}, \mathrm{SO}_{2}, \mathrm{NO}_{\mathrm{x}}, \mathrm{O}_{3}, \mathrm{PHAs}$ (polycyclic aromatic hydrocarbon), and other organic pollutants), the physical and chemical properties of leaves also provide favorable conditions to allow for the adhesion of particulate matter [11]. Therefore, increasing the surface coverage rate by planting trees can effectively reduce the concentration of air pollutants and help purify air $[12,13]$ The design of vegetation is important because it can either reduce or increase air pollutant concentrations; for example, USA and England have planted trees to reduce air pollution particulate matter by adopting good designs [14]. Nowak et al. [15] applied the i-tree model to estimate and evaluate the amount of $\mathrm{PM}_{2.5}$ removed by trees in ten cities in the United States; they concluded that the total amount of air particulate matter removed by trees varied from $4.7 \mathrm{t}$ to $64.5 \mathrm{t}$ each year. Forest trees and shrubs throughout the United States could remove 21,500 $\mathrm{t}$ of $\mathrm{PM}_{10}$ each year. McDonald et al. [16] determined that the $\mathrm{PM}_{10}$ concentration could be reduced effectively by $2 \%-10 \%$ if the tree-planting area in British cities comprised one-quarter of the city area. However, different plants exhibit significantly different dust-retention capacity for air particulate matter. The dust-retention mechanism of plants for $\mathrm{PM}_{2.5}$ and other particulate matter has not been comprehensively evaluated [17]. 
In the current study, we evaluated particle capturing capacities, including the influencing factors, of leaves from six major tree species in Beijing. The main objectives of the present study were as follows: (1) to investigate the seasonal variation in particle capturing capacity of leaves from six major tree species in Beijing; (2) to observe the morphological features of the leaf surface and correlate them with the amount of collected particles; and (3) to select the optimal plant species to be used to reduce urban air particulate matter and associated chemicals to improve air quality.

\section{Materials and Methods}

\subsection{Study Sites}

Beijing Botanical Garden $\left(39^{\circ} 59^{\prime} 54^{\prime \prime} \mathrm{N}, 116^{\circ} 12^{\prime} 12^{\prime \prime} \mathrm{E}\right)$ is located at the foot of the Western Hills and is very close to 5th Ring Road in Beijing, with a total planned area of $400 \mathrm{hm}^{2}$. The garden consists of 1.5 million plants, comprehensively integrating plant resource exhibition and protection, scientific research, and recreation. The main vegetation types include Pinus tabuliformis, Pinus bungeana, Platycladus orientalis, Pinus koraiensis, Ginkgo biloba, Robinia pseudoacacia, Buxus megistophylla, Populus tomentosa, and Salix matsudana. The vegetation coverage rate is more than $80 \%$. The species in the park represent typical vegetation types of North China.

\subsection{Plant Sampled Species}

Samples of P. tabuliformis, P. bungeana, A. truncatum, P. tomentosa, S. matsudana, and G. biloba commonly grown along 5th Ring Road in Beijing were collected. Leaves from thesi $x 6$ sample tree species were selected $2-3 \mathrm{~m}$ above the ground from the individual tree, with three 3 replicates. The number of leaves collected was based upon ensuring the same total area for each sample, as shown in Table 1. After cutting, leaf samples were immediately placed into a dust-free paper bag, which can prevent further exposure of the leaves to particles. Then the samples were transported to the laboratory and analyzed. All samples were collected after 10 days without rain. The same leaves were divided into three groups (wind tunnel, atomic force microscopy (AFM), microstructure).

Table 1. Height and breast-height diameter as well as amount of sampled leaves of six tree species.

\begin{tabular}{cccc}
\hline \multirow{2}{*}{ Species } & \multicolumn{3}{c}{ Characteristic of Species } \\
\cline { 2 - 4 } & Height/m & Diameter/cm & Amount of Sampled Leaves (g) \\
\hline Pinus tabuliformis & $5.50 \pm 1.00$ & $10.15 \pm 0.23$ & 100 \\
Pinus bungeana & $5.00 \pm 1.50$ & $10.22 \pm 0.42$ & 100 \\
Populus tomentosa & $15.00 \pm 2.00$ & $15.5 \pm 0.15$ & 200 \\
Ginkgo biloba & $12.50 \pm 1.50$ & $12.34 \pm 0.22$ & 150 \\
Acer truncatum & $6.50 \pm 0.50$ & $10.67 \pm 0.13$ & 150 \\
Salix matsudana & $12.50 \pm 1.50$ & $13.54 \pm 0.08$ & 150 \\
\hline
\end{tabular}

For each species, leaf samples were from 1 April to 31 October 2014. In the sampling period, in order to reduce the impact of environmental factors as far as possible, we ensured that the weather condition patterns (including wind speed, temperature, and humidity) experienced by sampled trees in study site were broadly similar (Table 2). 
Table 2. The weather conditions in Beijing Botanical Garden, 2014. *

\begin{tabular}{cccccc}
\hline Date time & Rain $(\mathbf{m m})$ & Temp $\left({ }^{\circ} \mathbf{C}\right)$ & RH $(\%)$ & Wind Speed $(\mathbf{m p h})$ & Wind Direction $\left({ }^{\circ}\right)$ \\
\hline 1 to 9 April. & 0 & $16.67 \pm 4.44$ & $36.32 \pm 17.93$ & $1.00 \pm 1.33$ & $181.08 \pm 10.77$ \\
12 to 21 May & 0 & $22.59 \pm 4.64$ & $43.84 \pm 17.65$ & $1.17 \pm 1.77$ & $171.03 \pm 19.83$ \\
12 to 21 June & 0 & $23.70 \pm 4.47$ & $62.12 \pm 19.36$ & $0.59 \pm 1.11$ & $142.96 \pm 14.88$ \\
2 to 11 July & 0 & $28.14 \pm 3.40$ & $65.97 \pm 23.11$ & $0.88 \pm 1.47$ & $146.59 \pm 28.51$ \\
15 to 24 August & 0 & $26.42 \pm 3.53$ & $65.78 \pm 17.99$ & $0.36 \pm 0.76$ & $130.80 \pm 26.99$ \\
3 to 12 September & 0 & $24.12 \pm 3.41$ & $60.99 \pm 17.51$ & $0.35 \pm 1.71$ & $164.72 \pm 4.78$ \\
10 to 19 October & 0 & $15.56 \pm 3.57$ & $55.44 \pm 23.18$ & $0.32 \pm 0.26$ & $167.33 \pm 14.97$ \\
\hline
\end{tabular}

* Values are average of 10 days. $\mathrm{RH}$ is relative humidity

\subsection{Specific Leaf Area Determination}

In the case of P. tabuliformis and P. bungeana, $100 \mathrm{~g}$ pine needles were sampled and their diameters and lengths were measured. Due to the needle shape, the average surface area of pine needles was calculated assuming a truncated cone, i.e., the average surface area of pine needles $\left(\mathrm{A}_{\text {pine }}\right)=(\pi / 2)$ $\times\left(d_{1}+d_{2}\right) \times\left((1 / 4) \times\left(d_{2}-d_{1}\right)^{2}+1^{2}\right)^{1 / 2}$, where $d_{1}=$ the average diameters of pine needles at the upper tip; $d_{2}=$ the average diameters of pine needles at the lower tip; $1=$ average length. Thus, the total surface area of pine needles used for each experimental run was calculated by counting the number of pine needles and multiplying it by the average surface area of pine needles. The leaves from broad-leaved tree species were scanned by a scanner (Canon LIDE 110, Canon, Tokyo, Japan), the scanned images were converted into black and white images, where the scanned image of each leaf appeared black against a white background. Then, the surface area of each tree leaf was obtained by the Adobe Photoshop CS2 program, by calculating the area of the black image.

\subsection{Adsorptive Amount for Dust Per Unit of Leaf Area}

The particle removal efficiency was measured in a wind tunnel, which was $0.5 \mathrm{~m}$ wide, $0.5 \mathrm{~m}$ high, and $1 \mathrm{~m}$ in length (Figure 2). Several leaves of the sample species were freshly cut on the day of the measurements. The leaves were laid flat and stacked up uniformly to ensure that most of the air stream passed through them. The total length of the wind tunnel occupied by branches was $1 \mathrm{~m}$. The experiment was carried out at a wind speed of $20 \mathrm{~m} / \mathrm{s}$. By using $20 \mathrm{~m} / \mathrm{s}$ wind speed, the potential for each leaf can be determined by dividing the total amount of particulate captured by the number of leaves.

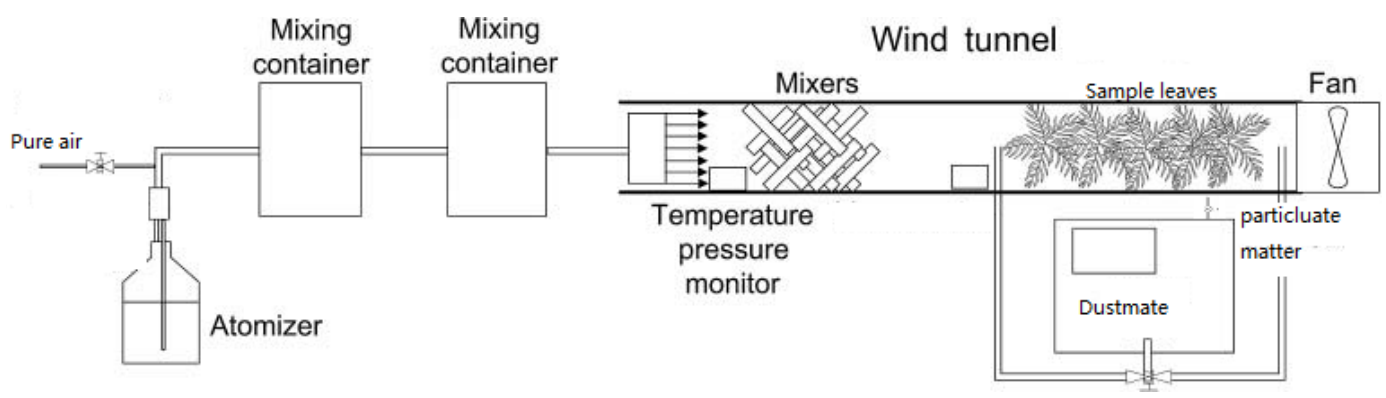

Figure 2. A sketch of the wind tunnel experimental setup.

The tunnel was sampling filtered room air. The room air aerosol number concentration was fairly constant $\left(<1 \mu \mathrm{g} / \mathrm{m}^{3}\right)$ and was around $10 \mathrm{~m}^{3}$. Firstly, sample leaves were placed in the wind tunnel, then the pure air that did not contain the particulate matter was introduced into the wind tunnel through a plenum with several openings. Secondly, a fan carried out at a wind speed of $20 \mathrm{~m} / \mathrm{s}$ to blow the sample leaves in tunnel. This process continued for about 6-10 $\mathrm{min}$, in order to ensure that all of the particulate matter on the surface of the leaves was suspended in the tunnel air. It has been confirmed that a wind speed of $20 \mathrm{~m} / \mathrm{s}$ and a duration of $6-10 \mathrm{~min}$ can remove $>80 \%$ particulate matter 
from leaves [18]. Lastly, the Dustmate (Turnkey, UK) instrument was used to measure the particulate concentration of the tunnel air.

The formula used to calculate the adsorptive amount of the particulate matter per unit of leaf area of different tree species is as follows: [19]

$$
M i=\sum_{1}^{n} \frac{m_{i j}}{S_{i}}
$$

where $M$ represents the mass of the captured particulate matter by leaf area of different tree species (unit: $\mu \mathrm{g} / \mathrm{cm}^{2}$ ), $i$ represents different tree species, $j$ represents the types of particulate species, $n=3$ different replicates, $S$ represents the leaf areas (unit: $\mathrm{cm}^{2}$ ), and $m_{i j}$ represents the mass of TSP, PM 10 , and $\mathrm{PM}_{2.5}$ (unit: $\mu \mathrm{g}$ ).

\subsection{AFM Scanning Features of the Leaves Surface}

We brought the leaves back to the laboratory, and removed the moisture on the leaf surface carefully with absorbent paper, and finally selected samples about $5 \mathrm{~mm} \times 5 \mathrm{~mm}$ in size. At normal temperature, we scanned and shot the samples using a scanning probe microscope (SPI3800-SPA-400, Seiko Instruments Inc., Kanagawa, Japan) and the maximum scanning range was $100 \mu \mathrm{m} \times 100 \mu \mathrm{m}$. All AFM images were obtained in height mode and were not processed in any way. The sampled leaf surfaces were examined by AFM (atomic force microscopy), which can determine several parameters, including the arithmetical mean deviation of the profile $(\mathrm{Ra})$, ten-point height of irregularities ( $\mathrm{Rz})$, and peak-to-valley value $(\mathrm{P}-\mathrm{V})$. Ra is commonly used to characterize the roughness of the surface.

\subsection{Microstructure of Leaves}

The fresh leaves were cut into $4 \times 4 \mathrm{~mm}$ small cubes from both sides in the middle of the leaves, and fixed in $2.5 \%$ (volume fraction) glutaraldehyde solution. After the samples were sprayed with conductive coating, the surface structures of the leaves were observed with a S-3400 scanning electron microscope (Hitachi, Japan), and the images were taken with appropriate scaling.

\subsection{Statistical Analysis}

Statistical analysis was performed with SPSS 15.0 software (SPSS software Co., New York, NY, USA). Analyses of variance (ANOVA) were applied to determine if significant differences in leaf PM accumulation and surface roughness occurred among different sampling times for each species and among species. Pearson's correlation analysis was conducted to test the relationship of the leaf PM retention amounts with leaf roughness. A given effect was assumed significant at $p<0.05$.

\section{Results and Analysis}

\subsection{Variation in the Capturing Capacity of Different Tree Species over Time}

Figures 3 and 4 show the variation in the capturing capacity of leaves from different tree species over time. The order was as follows: P. tabuliformis $>$ P. bungeana $>$ S. matsudana $>$ A. truncatum $>$ G. biloba $>$ P. tomentosa. During the monitoring period (from April 2014 to October 2014), the capturing capacity of the leaves from needle-leaved tree species was greater than that of the broad-leaved tree species for both coarse $(>10 \mu \mathrm{m})$ and fine $(<2.5 \mu \mathrm{m})$ particulate matter. Among the broad-leaved tree species, S. matsudana had the strongest capturing capacity, whereas those of $P$. tomentosa and G. biloba exhibited the weakest capturing capacity. However, statistical analysis by 2-way ANOVA revealed a significant difference in variation trend between species with TSP over time $(p<0.05)$. For example, the broad-leaved tree species clearly showed a $\cap$-shape pattern-initially increasing and eventually decreasing, meanwhile $P$. tabuliformis and $P$. bungeana did not clearly exhibit a $\cap$-shape pattern-initially decreasing and eventually increasing (Figure 3). Capturing capacity reached its 
maximum from April to May, obtained its lowest from July to August, and gradually increased after October. The capturing capacity for $\mathrm{PM}_{10}$ was basically the same as the absorption capacity for TSP. However, no significant difference in the variation trend with respect to $\mathrm{PM}_{2.5}$ was indicated between species over time $(p>0.05)$ (Figure 4$)$.

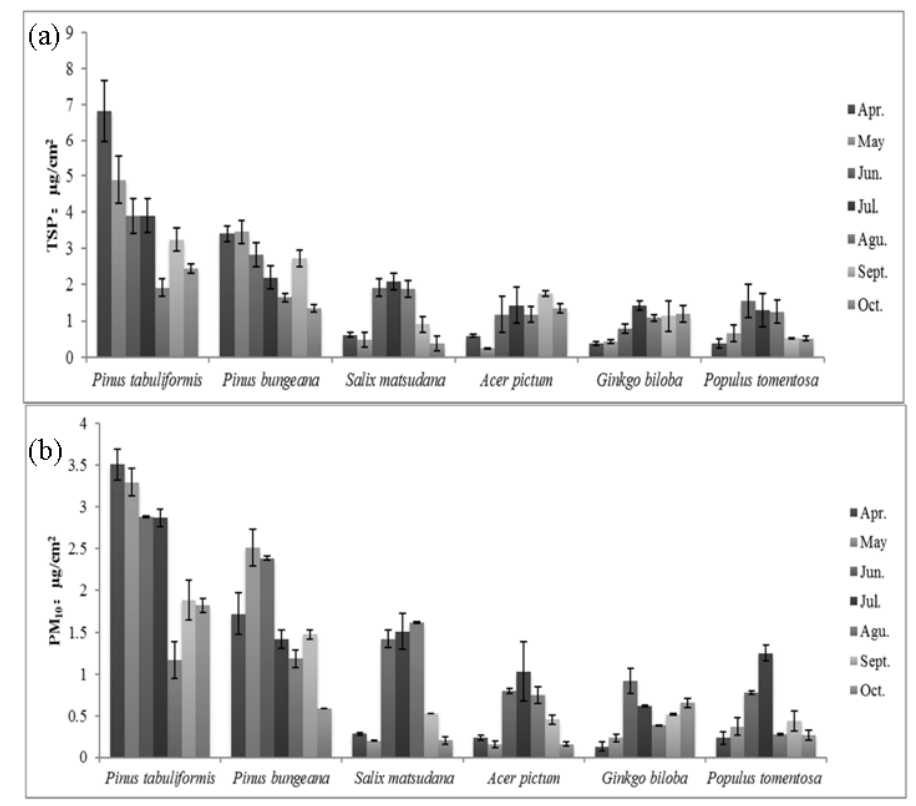

Figure 3. The amount of particulate matter captured by different species. Vertical bars represent + standard error; $n=3$. Statistical analysis by 2-way ANOVA revealed that differences between species were significant $(p<0.05)$, as were differences between variations over time in TSP (a) and PM $_{10}$ (b) $(p<0.05)$.

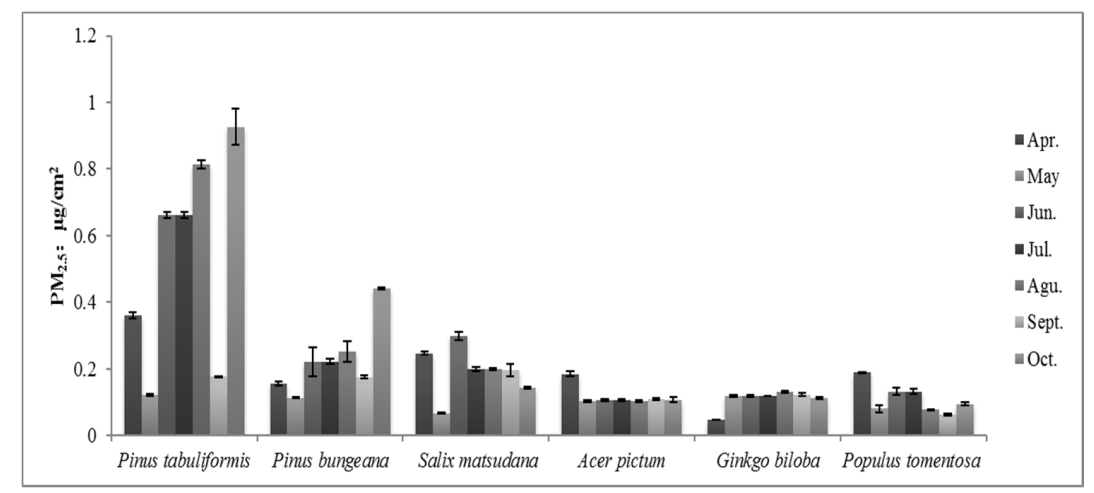

Figure 4. The amount of particulate matter captured by different species. Vertical bars represent + standard error; $n=3$. Statistical analysis by 2-way ANOVA revealed that differences between species were significant $(p<0.05)$. However, differences between variations over time in $\mathrm{PM}_{2.5}$ were not significant.

\subsection{Surface Morphological Structures of Leaves from Different Trees}

Figure 5 presents the surface microstructures of leaves from six tree species. The surface of P. tabuliformis and P. bungeana showed obvious grooves as well as peaks and valleys. The stomatic arrangement density and the epicuticular wax of P. tabuliformis and P. bungeana were higher than those of P. tomentosa, G. biloba, A. truncatum, and P. tomentosa. The stomas of P. tabuliformis (A) are circular and arranged vertically, have higher density, and show irregular particulate matter captured on it. This structure helps position dust particulate matter close to the stomas on the leaf surfaces because of the 
irregularity of the cell arrangement; thus, the dust becomes concentrated in the stomas. The leaf texture is arranged closely with raised bars as well as rough and irregular surface. P. bungeana (B) has oval stomas that are larger than those of P. tabuliformis. However, P. bungeana leaves are smoother around the stomas, compared with P. tabuliformis, and show less captured particulate matter. P. bungeana leaves exhibit an irregular texture with sheet distribution and no observable pubescence, with waxes on the leaf surface. G. biloba (C) leaves have a smooth surface and a low density of clear and distinct stomas, with neither wax nor epidermal cilium. P. tomentosa (D) leaves have an epidermis that tends to be smooth and stomas that are considerably small, sunk under the corneum, and completely surrounded by the corneum arch covering protuberances, with no secretion. The texture is clear and distinct with shallow mesh ornamentation, no epidermal pubescence and glands, and only a few captured particulate matters on the surface. A. truncatum (E) leaves exhibit a radial and parallel distribution of their stomas, with some shallow ridges and similar mesh and honeycomb trench organizations with clear and distinct but irregular texture. Both the front and back of A. truncatum leaves have folds. S. matsudana $(\mathrm{F})$ leaves have larger and smoother stomata with a lower density and smaller openings and no obvious fluctuation, as such, the leaves show low peaks and valleys and less bulges. Around the stomata, S. matsudana leaves exhibit an intensive and shallow linear decoration and more surface cilia, which are soft and long with short cylindrical forms and arranged sparsely.

The mean value of roughness was measured on the front and back of the leaves from the six tree species. Except for P. tabuliformis and P. bungeana, the roughness of all leaves exhibited a significant correlation with dust absorption. With increased leaf roughness, the absorption of the unit leaf area also increased, as shown in Figure 6. The mean roughness of the front and back sides of the leaves, in descending order, are as follows: S. matsudana $(276.52 \pm 30.82 \mathrm{~nm})>$ A. truncatum $(133.05 \pm 23.05 \mathrm{~nm})$ $>$ G. biloba $(129.17 \pm 35.90 \mathrm{~nm})>$ P. tomentosa $(72.65 \pm 7.98 \mathrm{~nm})$. This sequence is similar to that of the absorption of the broad-leaved tree species per unit leaf area. Therefore, the roughness of the leaves from broad-leaved tree species exhibits a positive correlation with $\mathrm{PM}_{2.5}$ absorptions in a unit leaf area; however, this does not apply in the leaves of coniferous trees [20].

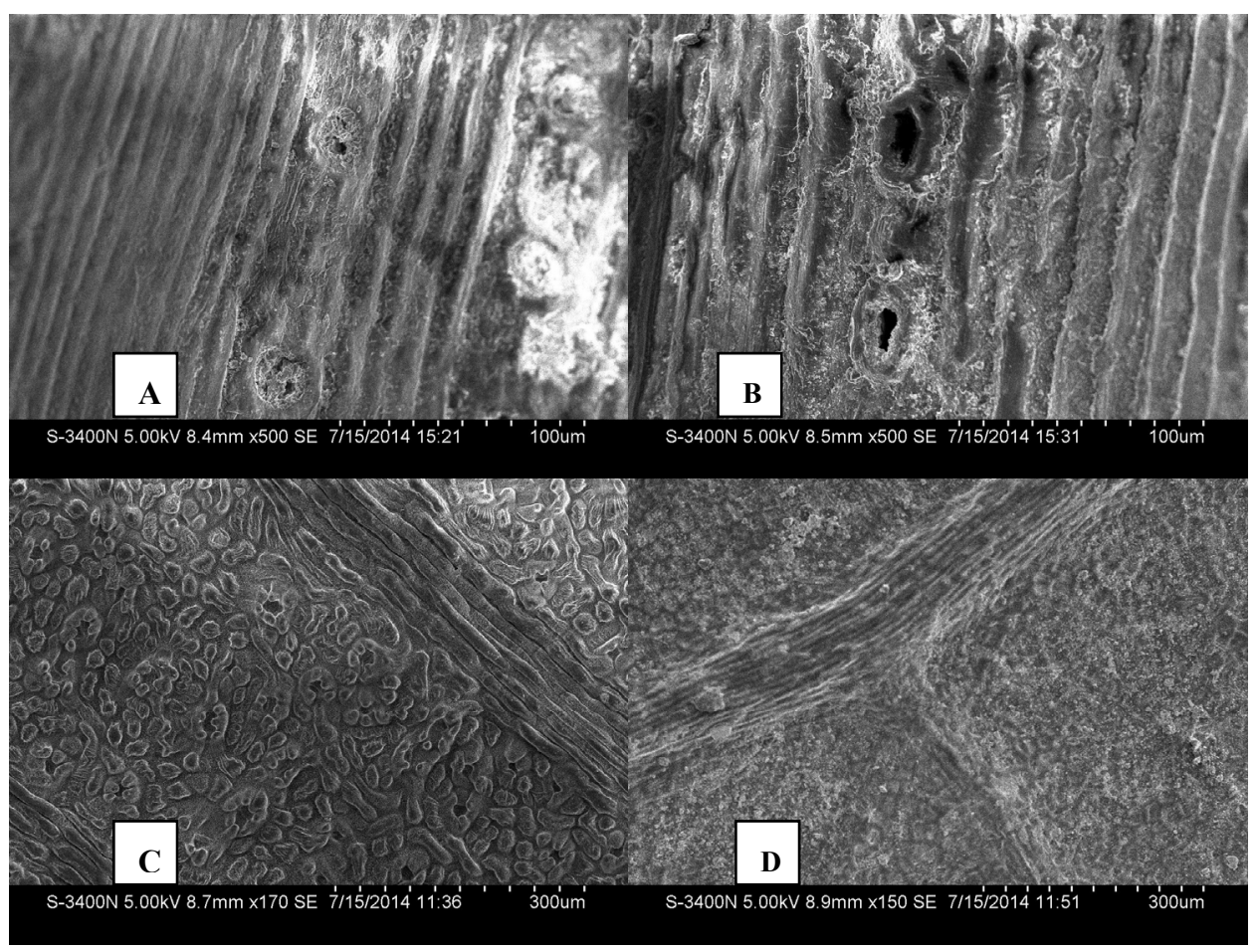

Figure 5. Cont. 


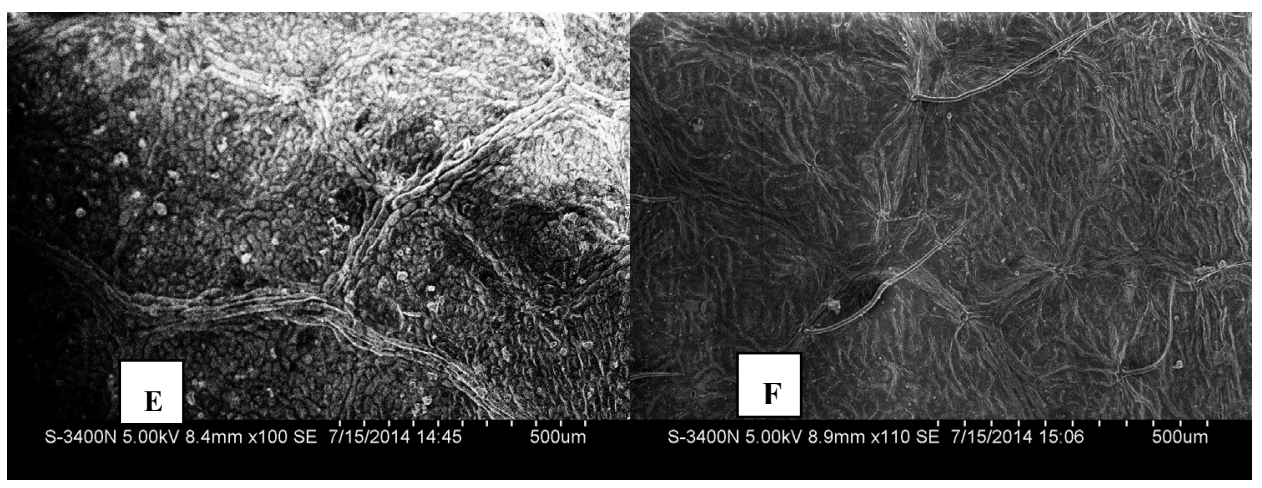

Figure 5. Microscopic structure of leaves of different tree species, (A): Pinus tabuliformis; (B): Pinus bungeana; (C): Ginkgo biloba; (D): Populus tomentosa; (E): Acer truncatum; (F): Salix matsudana.

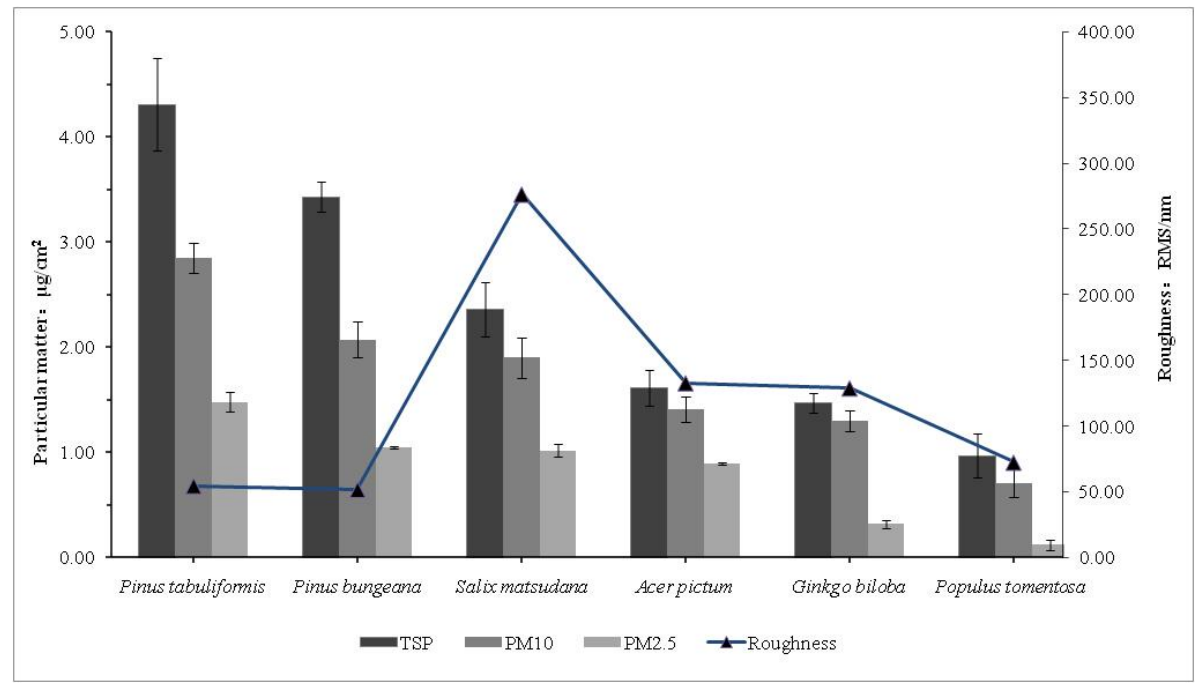

Figure 6. Relationship between the capture ability and roughness of leaves of different species. Vertical bars represent + standard error; $n=3$. Statistical analysis by 2 -way ANOVA revealed that differences between roughnesses in relation to the amount of particulate captured in Pinus tabuliformis and Pinus bungeana were not significant. However, differences between roughness and Salix matsudana, Ginkgo biloba, Acer truncatum, and Populus tomentosa were significant $(p<0.05)$.

\section{Discussion}

In the current study, $\mathrm{PM}_{2.5}$ absorptions by P. tabuliformis and P. bungeana reached their maximum in October $\left(0.93 \pm 0.054 \mu \mathrm{g} / \mathrm{cm}^{2}\right.$ and $0.44 \pm 0.032 \mu \mathrm{g} / \mathrm{cm}^{2}$, respectively) and their minimum in May and August $\left(0.12 \pm 0.002 \mu \mathrm{g} / \mathrm{cm}^{2}, 0.18 \pm 0.001 \mu \mathrm{g} / \mathrm{cm}^{2} ;\right.$ and $0.11 \pm 0.001 \mu \mathrm{g} / \mathrm{cm}^{2}, 0.21 \pm 0.002 \mu \mathrm{g} / \mathrm{cm}^{2}$, respectively). This variation may be attributable to climate. Windier days were observed in Beijing from May to June more than in any other period. Influenced by strong winds, less $\mathrm{PM}_{2.5}$ particulate matter may settle on the leaf surface and be captured. Many rainy days were recorded in August. Similar to the wind, the rain may wash off the particulate matter, resulting in less material for the leaves to capture. The capturing capacity for $\mathrm{PM}_{2.5}$ by the leaves from broad-leaved tree species slightly varied over time, which may be attributed to the morphological structure of the leaf surface $[21,22]$. Moreover, we observed a significant change in leaf PM accumulation for the six sampled species throughout the growing season [23-25]. 
Table 3. Surface structural properties of the plants over time.

\begin{tabular}{|c|c|c|c|c|c|c|c|c|c|c|c|c|}
\hline \multirow[b]{2}{*}{ Name of Plant } & \multicolumn{4}{|c|}{ Spring } & \multicolumn{4}{|c|}{ Summer } & \multicolumn{4}{|c|}{ Autumn } \\
\hline & $\begin{array}{l}\text { Epicuticular } \\
\text { Wax }\end{array}$ & Cuticle & Epidermis & Stomata & $\begin{array}{l}\text { Epicuticular } \\
\text { Wax }\end{array}$ & Cuticle & Epidermis & Stomata & $\begin{array}{l}\text { Epicuticular } \\
\text { Wax }\end{array}$ & Cuticle & Epidermis & Stomata \\
\hline Pinus tabuliformis & Granular & Wavy & Dust laden & $\begin{array}{l}\text { High frequency } \\
\text { and dust filled }\end{array}$ & Sparse & Wavy & $\begin{array}{l}\text { Wall well } \\
\text { defined }\end{array}$ & $\begin{array}{l}\text { High Frequency } \\
\text { and not dust filled }\end{array}$ & $\begin{array}{l}\text { Sparse, finally } \\
\text { granulated }\end{array}$ & Wavy & Dust laden & $\begin{array}{l}\text { High Frequency } \\
\text { and dust filled }\end{array}$ \\
\hline Pinus bungeana & Granular & Wavy & Dust laden & $\begin{array}{l}\text { High frequency } \\
\text { and dust filled }\end{array}$ & Sparse & Wavy & $\begin{array}{l}\text { Wall well } \\
\text { defined }\end{array}$ & $\begin{array}{l}\text { High Frequency } \\
\text { and not dust filled }\end{array}$ & $\begin{array}{l}\text { Sparse, finally } \\
\text { granulated }\end{array}$ & Wavy & Dust laden & $\begin{array}{l}\text { High Frequency } \\
\text { and dust filled }\end{array}$ \\
\hline Salix matsudana & Inconspicuous & Smooth & $\begin{array}{l}\text { Wall well } \\
\text { defined }\end{array}$ & Less stomata & Inconspicuous & Wrinkled & $\begin{array}{l}\text { Irregularly } \\
\text { fused }\end{array}$ & Sunken & Inconspicuous & Wrinkled & $\begin{array}{l}\text { Irregularly } \\
\text { fused }\end{array}$ & Less stomata \\
\hline Acer truncatum & NR & Striated & $\begin{array}{l}\text { Wall well } \\
\text { defined }\end{array}$ & Slightly Elevated & Inconspicuous & Disorganized & Slightly clear & Sunken & Inconspicuous & Disorganized & Slightly clear & Slightly Elevated \\
\hline Populus tomentosa & Sparse & Rugose & $\begin{array}{l}\text { Wall well } \\
\text { defined }\end{array}$ & $\begin{array}{l}\text { Elongated with } \\
\text { clear rims }\end{array}$ & Inconspicuous & $\begin{array}{l}\text { Pattern } \\
\text { deformed }\end{array}$ & $\begin{array}{l}\text { Outer layer } \\
\text { broken }\end{array}$ & Broken & Inconspicuous & $\begin{array}{l}\text { Pattern } \\
\text { deformed }\end{array}$ & $\begin{array}{l}\text { Outer layer } \\
\text { broken }\end{array}$ & Broken \\
\hline
\end{tabular}

NR, not recorded. 
Throughout the study, we found that the leaves from needle-leaved tree species were perennial, the surface structure of the leaves could change the capturing capacity, and that capturing capacity was less affected by the roughness of the leaves $(r=0.42,0.41)$. By contrast, the capturing capacity of the leaves from the broad-leaved tree species was strongly influenced by the roughness of leaves in different seasons. However, for both needle-leaved and broad-leaved tree species, variation in capturing capacity of the leaves for $\mathrm{PM}_{2.5}$ was influenced significantly by structural characteristics, including the stomata, epicuticular wax, cuticle, epidermis, and other surface features of leaves (Table 3). The ridges and grooves of epidermal cells and the density of micro-configurations, such as cell peaks, valleys, and recesses, determined the leaf surface roughness [26,27]. In the current study, the micro-roughness of the leaf surfaces correlates well with the density of particles settling upon leaf surfaces over time in all of the test species except for P. tabuliformis and P. bungeana. As shown in Table 4, the surface roughness of the leaves of broad-leaved tree species is greater than that of the leaves of needle-leaved tree species. However, the dust-retention ability of the leaves of needle-leaved tree species is higher than that of the broad-leaved tree species [28,29]. Thus, for needle-leaved tree species, the main factors affecting particle capturing capacity include epicuticular wax, stomata, and cuticle. The surface roughness of the leaves from the broad-leaved tree species is directly proportional to the capturing capacity of the leaves; this surface roughness and other morphological features significantly contribute to the capturing capacity of the leaves.

Table 4. Statistics related to correlation between roughness and total particles captured for leaves of different trees. $r$ refers to correlation coefficient. Statistical significance $(* * p<0.05)$ is based on the t-test *

\begin{tabular}{ccccccc}
\hline Species & Roughness & Std. Error & Total Particles & Std. Error & $\boldsymbol{r}$ & Significance \\
\hline Pinus tabuliformis & 54.81 & 3.19 & 8.64 & 0.22 & 0.42 & $* *$ \\
Pinus bungeana & 51.87 & 1.81 & 6.55 & 0.25 & 0.41 & $* *$ \\
Salix matsudana & 276.52 & 30.82 & 5.28 & 0.31 & 0.93 & $* *$ \\
Acer truncatum & 133.05 & 23.05 & 3.91 & 0.18 & 0.85 & $* *$ \\
Ginkgo biloba & 129.17 & 35.90 & 3.09 & 0.33 & 0.87 & $* *$ \\
Populus tomentosa & 72.65 & 7.98 & 1.80 & 0.15 & 0.82 & $*$ \\
\hline \multicolumn{7}{c}{ * Roughness-nm, Total particles $=\mathrm{TSP}+\mathrm{PM}_{10}+\mathrm{PM}_{2.5}-\mu \mathrm{g} / \mathrm{cm}^{2}}$. \\
\end{tabular}

Particle retention in leaves is not only affected by leaf related factors but by external conditions as well. These conditions include wind speed and rainfall, among others. However, these factors remain undetermined, and several studies suggest that the amount of particles settling upon leaf surfaces was affected by local rainfall. Rainfall can wash away the particles from the leaf surface; however, the amount of rain that can markedly influence this process remains inconclusive [30,31]. It is also important to consider the potential impacts of particle retention on plant health, as when the particles on the surface of leaves reach a certain amount, the air particles can also affect plant growth, photosynthesis, respiration, and transpiration [32-35]. More research is needed to explore and discuss these factors in the future.

\section{Conclusions}

The absorption capacity of leaves from different tree species varied in different growth periods. During the observation period from 1 April 2014 to 31 October 2014, the capturing capacity of P. tabuliformis and P. bungeana leaves for TSP and $\mathrm{PM}_{10}$ initially decreased and then increased over time; however, the $\mathrm{PM}_{2.5}$ capturing capacity was irregular. The TSP and $\mathrm{PM}_{10}$ capturing capacity of the leaves from broad-leaved tree species initially increased and then decreased over time. $\mathrm{PM}_{2.5}$ remained steady except during the leaf-expansion period. Observation of leaf features by AFM and microstructures indicated that the surface roughness and surface structure of leaves affect the capturing capacity of leaves for particulate matter; however, the degree of this effect varies between 
different tree species. The epicuticular wax, cuticle, and stomata of P. tabuliformis and P. bungeana can more effectively capture particulate matter in air, particularly $\mathrm{PM}_{2.5}$; however, roughness in G. biloba, P. tomentosa, A. truncatum, and S. matsudana is the main factor.

Acknowledgments: This work was financially supported by grants from National Natural Science Foundation of China (Grant No: 31600359), the fundamental Research Funds for CAF (Grant No. CAFBB2016QA007), and the Beijing Municipal Education Commission (CEF-PXM2017_014207_000043).

Author Contributions: B.W. and X.N. conceived of and designed the experiments. W.K.Z. performed the experiments. X.N. and W.K.Z. analyzed the data and wrote the paper.

Conflicts of Interest: The authors declare no conflict of interest.

\section{References}

1. Amann, M.; Klimont, Z.; Wagner, F. Regional and global emissions of air pollutants: Recent trends and future scenarios. Annu. Rev. Environ. Resour. 2013, 38, 31-55. [CrossRef]

2. Burtraw, D.A.; Krupnick, K.; Palmer, A.; Paul, M.; Cary, B. Ancillary Benefits of Reduced Air Pollution in the US from Moderate Greenhouse Gas Mitigation Policies in the Electricity Sector. J. Environ. Econ. Manag. 2003, 45, 650-673. [CrossRef]

3. Clark, N.A.; Demers, P.A.; Karr, C.J.; Koehoorn, M.; Lencar, C. Effect of early life exposure to air pollution on development of childhood asthma. Environ. Health Perspect. 2010, 118, 284-290. [CrossRef] [PubMed]

4. Zhang, W.; Wang, B.; Niu, X. Study on the adsorption capacities for airborne particulates of landscape plants in different polluted regions in Beijing (China). Environ. Res. Public Health 2015, 12, 9623-9638. [CrossRef] [PubMed]

5. Jing, J.; Gang, W.; Xilong, D.; Yang, H. Evaluation of capturing Haze $\mathrm{PM}_{2.5}$ Fine Particulate Matter with Plants in Beijing-Tianjin-Hebei Region in China. Sci. China Earth Sci. 2013, 43, 694-699.

6. Seinfeld, J.H. Air Pollution Physical and Chemical Fundamentals; McGraw-Hill: New York, NY, USA, 1975; pp. 1-523.

7. Matsuda, K.; Fujimura, Y.; Hayashi, K.; Takahashi, A.; Nakaya, K. Deposition velocity of PM2.5 sulfate in the summer above a deciduous forest in central Japan. Atmos. Environ. 2010, 44, 4582-4587.

8. National Bureau of Statistics of China. China Statistical Yearbook-2014; China Statistics Press: Beijing, China, 2014.

9. Chen, B.; Lu, S.W.; Li, S.N.; Wang, B. Impact of fine particulate fluctuation and other variables on Beijing's air quality index. Environ. Sci. Pollut. Res. 2015, 22, 5139-5151. [CrossRef] [PubMed]

10. Hwang, H.J.; Yook, S.J.; Ahn, K.H. Experimental investigation of submicron and ultrafine soot particle removal by tree leaves. Atmos. Environ. 2011, 45, 6987-6994. [CrossRef]

11. Räsänen, J.V.; Holopainen, T.; Joutsensaari, J. Particle capture efficiency of different-aged needles of Norway spruce under moderate and severe drought. Can. J. For. Res. 2014, 44, 831-835. [CrossRef]

12. Beckett, K.P.; Freer Smith, P.H.; Taylor, G. Effective tree species for local air quality management. J. Arboric. 2000, 26, 12-19.

13. Beckett, K.P.; Freer Smith, P.H.; Taylor, G. Particulate pollution capture by urban trees: Effect of species and winds peed. Glob. Chang. Biol. 2000, 6, 995-1003. [CrossRef]

14. Tallis, M.; Taylor, G.; Sinnett, D.; Freer-Smith, P. Estimating the removal of atmospheric particulate pollution by the urban tree canopy of London, under current and future environments. Landsc. Urban Plan. 2011, 103, 129-138. [CrossRef]

15. Nowak, D.J.; Hirabayashi, S.; Bodine, A.; Hoehn, R. Modeled $\mathrm{PM}_{2.5}$ removal by trees in ten US cities and associated health effects. Environ. Pollut. 2013, 178, 395-402. [CrossRef] [PubMed]

16. Mcdonald, A.G.; Bealey, W.J.; Fowler, D.; Dragosits, U.; Skiba, U. Quantifying the effect of urban tree planting on concentrations and depositions of $\mathrm{PM}_{10}$ in two UK conurbations. Atmos. Environ. 2007, 41, 8455-8467. [CrossRef]

17. Lei, W.; Shangyu, G.; Lianyou, L.; Ha, S. Atmospheric particle-retaining capability of eleven garden plant species in Beijing. Chin. J. Appl. Ecol. 2006, 17, 597-601. 
18. Yaoyao, F. Quantitative Research on Regional Forest PM-Capturing Capability and Analysis of the Related Leaf Micro-Morphology Impact: A Case Study of Shaanxi Central Plain; Chinese Academy of Forestry: Beijing, China, 2015.

19. Bing, W.; Weikang, Z.; Xiang, N.; Jinsong, W.; Xiaoyan, W. Particulate Matter Adsorption Capacity of 10 Evergreen Species in Beijing. Environ. Sci. 2015, 36, 37-42.

20. Wang, H.; Shi, H.; Li, Y.; Yu, Y.; Zhang, J. Seasonal variations in leaf capturing of particulate matter, surface wettability and micromorphology in urban tree species. Front. Environ. Sci. Eng. 2013, 7, 579-588. [CrossRef]

21. Zheng, M.; Salmon, L.G.; Schauer, J.J.; Zeng, L.; Kiang, C.S. Seasonal Trends in PM $_{2.5}$ Source Contributions in Beijing, China. Atmos. Environ. 2005, 39, 3967-3976. [CrossRef]

22. Mitchell, R.; Maher, B.A.; Kinnersley, R. Rates of particulate pollution deposition onto leaf surfaces: Temporal and inter-species magnetic analyses. Environ. Pollut. 2010, 158, 1472-1478. [CrossRef] [PubMed]

23. Sæbø, A.; Popek, R.; Nawrot, B.; Hanslin, H.M.; Gawronska, H. Plant species differences in particulate matter accumulation on leaf surfaces. Sci. Total Environ. 2012, 427, 347-354. [CrossRef] [PubMed]

24. Lu, L.; Dongsheng, G.; Yongqin, C. Morphological structure of leaves and dust-retaining capability of common Street tress in Guangzhou Municipality. Acta Ecol. Sin. 2013, 33, 2604-2614. [CrossRef]

25. Terzaghi, E.; Wild, E.; Zacchello, G.; Cerabolini, B.E.L.; Jones, K.C. Forest Filter Effect: Role of leaves in capturing/releasing air particulate matter and its associated PAHs. Atmos. Environ. 2013, 74, 378-384. [CrossRef]

26. Chenxi, Z.; Yujie, W.; Yun-qi, W.; Hui-lan, Z.H. Interactions between fine particulate matter $\left(\mathrm{PM}_{2.5}\right)$ and vegetation: A review. Chin. J. Ecol. 2013, 32, 2203-2210.

27. Hailong, W.; Xinxiao, Y.; Chen, S.; Yan, Z.H.; Zhenming, Z.H. Advances in the study of $\mathrm{PM}_{2.5}$ characteristic and the regulation of forests to $\mathrm{PM}_{2.5}$. Sci. Soil Water Conserv. 2012, 10, 116-122.

28. Freer-Smith, P.H.; Beckett, K.P.; Taylor, G. Deposition velocities to Sorbus aria, Acer campestre, Populus deltoides $\times$ trichocarpa 'Beaupre', Pinus nigra and $\times$ Cupressocyparis leylandii for coarse, fine and ultra-fine particles in the urban environment. Environ. Pollut. 2005, 133, 157-167. [CrossRef] [PubMed]

29. Shuxin, F.; Hai, Y.; Shimingyue, Q. Dust capturing of twenty-six deciduous broad-leaved trees in Beijing. Chin. J. Plant Ecol. 2015, 39, 736-745.

30. Huixia, W. Mechanisms of Plant Leaves Based on Leaf Surface wettability on rainfall Interception and Dust-Capturing; Xi'an University of Architecture \& Technology: Xi'an, China, 2012.

31. Rai, A.; Kulshreshtha, K.; Srivastava, P.K.; Mohanty, C.S. Leaf surface structure alterations due to particulate pollution in some common plants. Environ. Syst. Decis. 2010, 30, 18-23. [CrossRef]

32. Rai, P.K. Impacts of particulate matter pollution on plants: Implications for environmental biomonitoring. Ecotoxicol. Environ. Saf. 2016, 129, 120-136. [CrossRef] [PubMed]

33. Tomašević, M.; Vukmirović, Z.; RajŠić, S.; Tasić, M.; Stevanović, B. Characterization of trace metal particles deposited on some deciduous tree leaves in an urban area. Chemosphere 2005, 61, 753-760. [CrossRef] [PubMed]

34. Huixia, W.; Yanhui, W.; Jia, Y.; Binze, X.; Hui, S. Multi-Scale Comparisons of Particulate Matter and Its Size Fractions Deposited on Leaf Surface of Major Greening Tree Species. Sci. Sylvie Sin. 2015, 51, 9-20.

35. Elena, P.; Tommaso, B.; Gianluca, G.; Pecchioli, L. Air quality impact of an urban park over time. Procedia Environ. Sci. 2011, 4, 10-16.

(c) 2017 by the authors. Licensee MDPI, Basel, Switzerland. This article is an open access article distributed under the terms and conditions of the Creative Commons Attribution (CC BY) license (http:/ / creativecommons.org/licenses/by/4.0/). 